\title{
Experimental study on the durability of the panel concrete
}

\author{
${ }^{\mathrm{a} C} \mathrm{C}$. WANG \& Y. LI , ${ }^{\mathrm{b}} \mathrm{H} . \mathrm{B} . \mathrm{JING}$ \\ ${ }^{a}$ Xi'an University of Technology, Xi'an, Shaanxi, China \\ ${ }^{b}$ China Water Resources Pearl River Planning Surveying \& Designing Co., Ltd. ( Shanghai \\ Branch ), Shanghai, China
}

\begin{abstract}
KEYWORD: Panel concrete; Durability; W/C ratio; Freeze-thaw; Sulfate attack
ABSTRACT: Freeze-thaw damage and sulfate attack are two important factors that affect the durability of panel concrete. The damage of panel concrete with w/c ratio of $0.45,0.42,0.38$ under the single freeze-thaw cycles, single sulfate attack and the alternation test in solutions of $5.0 \% \mathrm{Na}_{2} \mathrm{SO}_{4}$ is studied, and analyzed the characteristics of mass loss and relative dynamic modulus. The results show that the w/c ratio have great influence on the panel concrete frost resistance and resistance to sulfate attack. The resistance of freeze-thaw and sulfate attack increased with the decreasing w/c ratio of panel concrete. Coupled deterioration of freeze-thaw cycle and sulfate attack is not a simple superposition effect, these two kinds of damage are promoting and influencing each other. The research methods and results can provide a reference for the durability of panel concrete.
\end{abstract}

\section{INTRODUCTION}

Concrete face slab is the main seepage body of the concrete faced rock-fill dams. During period of water storage, concrete face slab will be affected by ambient medium such as water, air, temperature and sunshine, and other effects. It is easy to make concrete produce a large number of cracks and some through the cracks are the main factors affecting the durability of panel concrete and safety (Gao \& Li 2013). So far engineering on concrete durability requirements is relatively high, concrete face should not only has high strength, high antifreeze impermeability, should also have low shrinkage rate to the damaging effects of external environment brought about by the freezing and thawing, dry and wet, carbonization resistance. According to the related reports (Liu 2001; Wang \& Yao 2001), there exist a lot of sulfate rich soils and more than 1000 salt lakes are scattered in Northwest China. In such regions, a large number of concrete structures are severely deteriorated and their service life is largely shortened, mainly because of the sulfate attack and freeze-thaw damage. Thus, studying the damage process of the concretes in these areas for a rapid development of the infrastructure in Northwest China is necessary.

In recent years, Chinese scholars have carried out some research work on concrete durability under the influence of freeze-thaw cycles and sulfate attack. Yang \& Ma (2004) studied on the Shuibuya concrete faced rock-fill dam, analyzing the panel concrete mix ratio and concrete improvement. They proposed a necessary condition for the anti corrosion durability of panel concrete and improve the ways to panel concrete frost resistance, crack resistance, anti permeability. Liang \& He (2009) according to panel concrete need to simplify the temperature control and improve the crack resistance and durability requirements, proposed high fly ash and super-plasticizer of concrete preparation method and experimental study. The results show that the amount of fly ash and super-plasticizer has an important influence on the durability of panel concrete. Ge \& Yang (2005) studied the durability of air entraining agent concrete and on air entraining agent concrete in the different sodium sulfate solution, pointed out that different strength of concrete in different liquid have different resistance, the amount of air entraining agent can improve the concrete frost resistance. Ma \& Huang (2001) studied Shuibuya concrete faced rock-fill dam, due to the basic theory, mechanism analysis and a large number of experimental research and calculation, concluded a number of important research results of the durability of panel concrete, especially for $200 \mathrm{~m}$ high concrete face rock-fill dam. Wang \& $\mathrm{Li}$ (1998) according to Xiaoshan Hydropower Station, the panel concrete of durability was studied, and 
the combination of Xiaoshan Hydropower Station panel concrete mix ratio design, conducted concrete face slab of systematic experimental study. These test results can solve the problem of frost resistance and durability of hydraulic concrete in cold regions.

At present, the durability of panel concrete is studied under the multi factors, especially the freezethaw damage and sulfate attack concrete durability research is relatively less (Li \& Wang 2015). In this paper, the w/c ratio is designed for the gradient, by freeze-thaw cycle test, sulfate erosion test and freeze-thaw cycles and sulfate erosion alternate test. After the test, the mass of concrete and relative dynamic modulus were measured. Comparative study on the coupled deterioration of panel concrete durability, it can provide a reference of panel concrete preparation and durability design.

Table 1. The mix proportion and mechanical property of concrete

\section{EXPERIMENTAL DETAILS}

\section{Materials and mix proportions}

Cement: Shaanxi Qinling cement of P.O42.5R. Fly ash: II grade fly ash in Weihe power plant. Aggregate: Ba River sand, fineness modulus of 2.5. Fenhe river pebbles, diameter of 5 16 mm. Superplasticizer: poly carboxylic acid high efficiency water reducing agent of Xi'an red flag additive factory. Air entraining agent: three high efficiency of the gas agent. Water: ordinary tap water. And the mechanical properties are shown in Table 1 with panel concrete.

\begin{tabular}{|c|c|c|c|c|c|c|c|c|c|c|}
\hline \multirow{3}{*}{ Number } & \multicolumn{8}{|c|}{ Concrete mix ratio } & \multirow{3}{*}{$\begin{array}{c}\mathrm{w} / \mathrm{c} \\
\text { ratio }\end{array}$} & \multirow[b]{2}{*}{$\begin{array}{c}28 \mathrm{~d} \\
\text { pressure } \\
\text { degree }\end{array}$} \\
\hline & Cement & Water & Sand & $\begin{array}{c}\text { Coarse } \\
\text { aggre- } \\
\text { gate }\end{array}$ & $\begin{array}{l}\text { Fine ag- } \\
\text { gregate }\end{array}$ & $\begin{array}{l}\text { Fly } \\
\text { ash }\end{array}$ & $\begin{array}{c}\text { Air en- } \\
\text { trainment } \\
\text { agent }\end{array}$ & $\begin{array}{c}\text { Super- } \\
\text { plasticizer }\end{array}$ & & \\
\hline & $\mathrm{kg} \cdot \mathrm{m}^{-3}$ & $\underset{3}{\mathrm{~kg} \cdot \mathrm{m}^{-}}$ & $\underset{3}{\mathrm{~kg} \cdot \mathrm{m}^{-}}$ & $\mathrm{kg} \cdot \mathrm{m}^{-3}$ & $\mathrm{~kg} \cdot \mathrm{m}^{-3}$ & $\%$ & $\%$ & $\%$ & & $(\mathrm{MPa})$ \\
\hline 1 & 287.4 & 142 & 654.4 & 635.2 & 635.2 & 15 & 0.03 & 1 & 0.45 & 29.8 \\
\hline 2 & 287.4 & 142 & 642.1 & 623.2 & 623.2 & 25 & 0.03 & 1 & 0.42 & 32.3 \\
\hline 3 & 287.4 & 142 & 626.7 & 614.5 & 614.5 & 35 & 0.03 & 1 & 0.38 & 36.1 \\
\hline
\end{tabular}

\section{Specimen preparation and Test methods}

Experiment with the same ratio of panel concrete specimens, single cycle of freezing and thawing in the specimen is divided into D1, D2, D3, single sulfate erosion time divided into L1, L2, L3, freezing and thawing cycles and sulfate attack alternate test is divided into DL1, DL2, DL3, a total of 27 specimens, the size of $100 \mathrm{~mm} \times 100 \mathrm{~mm} \times 400 \mathrm{~mm}$. Concrete pouring $24 \mathrm{~h}$ after stripping, after the specimens in standard curing indoor curing $28 \mathrm{~d}$, natural curing for $60 \mathrm{~d}$.

Single freeze-thaw cycle test: test method according to GB/T82-09 "Standard for test method of long-term performance and durability of ordinary concrete", choose the" quick freezing method "as the freeze-thaw test. The mass loss rate and relative dynamic modulus of the sample were measured at the end of every 25 freeze-thaw cycles. Single sulfate attack test: test method also according to GB/T82-09 "Standard for test method of long-term performance and durability of ordinary concrete", choose the" Sulfate wet and dry cycle test "as the sulfate attack test. The mass loss rate and relative dynamic modulus of the sample were measured at the end of every 15 sulfate attack cycles. freeze-thaw and sulfate attack alternate test: firstly the freeze-thaw cycle test was carried out, after 25 cycles, the samples were taken out to carry out the drying and wetting cycle test for 15 times. Then take out the test piece to test its mass and relative dynamic modulus. The above process is 1 cycle, and the process is repeated until the end of the test.

\section{Arrangement and analysis of test results}

The evaluation index of this test is the mass loss rate and relative dynamic modulus of concrete, the average value of the test results of 3 specimens was measured.

Equation 1 was used to calculate the weight loss, as shown below. 
$W_{n}=\frac{G_{0}-G_{n}}{G_{0}} \times 100$

where $W_{n}=$ the weight loss of panel concrete specimens at $n$ cycles (\%); $G_{0}=$ the average weight of panel concrete specimens at the beginning of the test $(\mathrm{kg})$; and $G_{\mathrm{n}}=$ the average weight of concrete specimens at $n$ cycles $(\mathrm{kg})$.

Equation 2 was used to calculate the relative dynamic modulus, as shown below.

$P_{n}=\frac{f_{n}^{2}}{f_{0}^{2}} \times 100$

where $P_{n}=$ the relative dynamic modulus of panel concrete specimens at $n$ cycles $(\%) ; f_{0}=$ the natural frequency of panel concrete specimens at the beginning of the test $(\mathrm{Hz})$; and $f_{n}=$ the average natural frequency of panel concrete specimens at $n$ cycles $(\mathrm{Hz})$.

\section{RESULTS AND DISCUSSION}

\section{Freezing and thawing cycle tests}

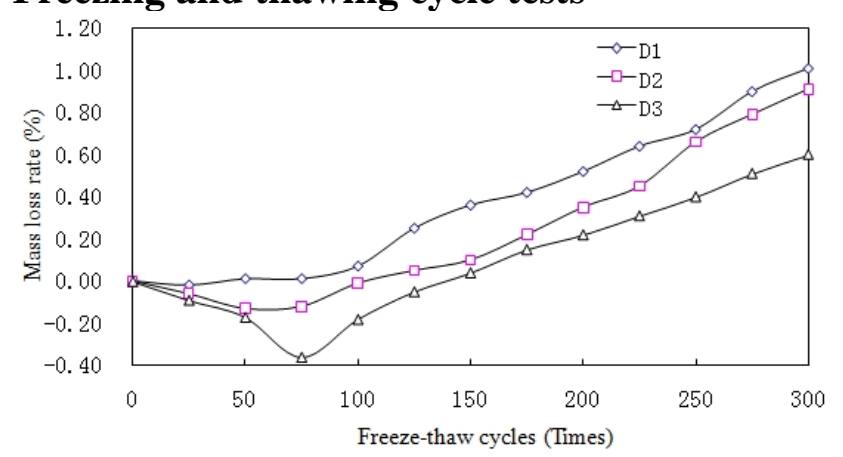

Figure 1. Mass loss in freeze-thaw test.

It can be concluded from Figure 1: during the initial freeze-thaw cycles, D1, D2, D3 specimens mass improved. The reason is that at the beginning stages of freeze-thaw test, the panel concrete specimens absorb water, surface dregs very little, so the mass increased. With the increase of the number of freeze-thaw cycles, some slight cracks appeared in internal and surface of panel concrete, resulting in mortar drop in the surface of specimen.Due to absorbed water mass less than droped mortar, so the mass of panel concrete begin to reduce. Therefore, we can see that the mass increases at first, with the increase of time, slowly decreases. D1, D2, D3 three curves, with the increase of freeze-thaw cycles, reach to 300 freeze-thaw cycles, it can be seen that the concrete mass loss rate of D1 is the biggest, and the mass loss rate of D3 is the smallest. With the decrease of w/c ratio, the freeze-thaw resistance of panel concrete face is gradually improved.

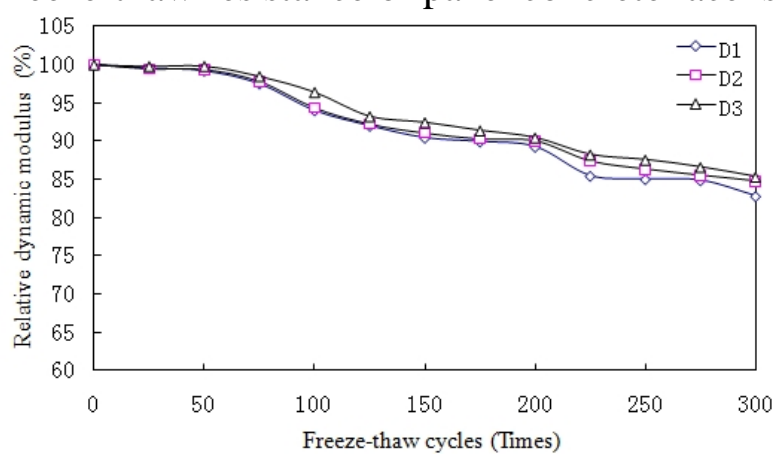

Figure 2. Relative dynamic modulus loss in freeze-thaw test.

It can be concluded from Figure 3: D1, D2, D3 panel concrete specimens, with the increase of freeze-thaw cycles, the relative dynamic modulus decreased. When the 300 freeze-thaw cycles were reached, the relative dynamic modulus of the D3 group was the largest, and the modulus of elasticity 
of the D1 group was the lowest. D3, D2, D1 modulus of elasticity decreased in turn, it can be seen that with the smaller w/c ratio, the greater the dynamic modulus of the panel concrete, the smaller the degree of deterioration of panel concrete.

\section{Sulfate attack test}

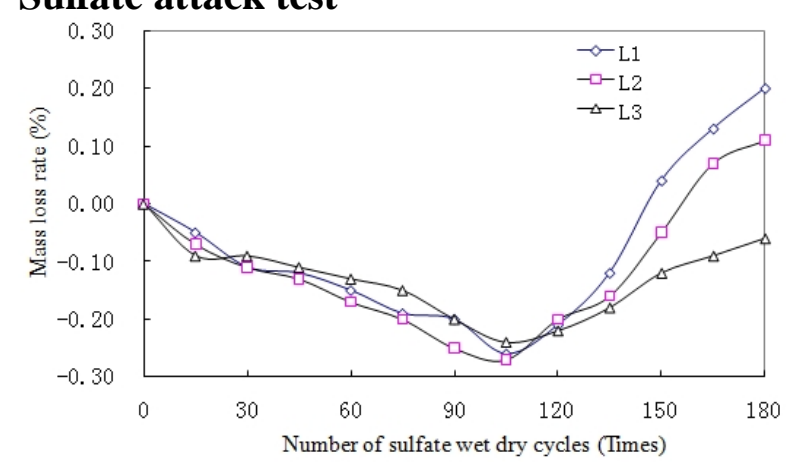

Figure3. Mass loss in sulfate attack.

It can be concluded from Figure 2: after 180 times of dry wet cycles, L2, L1, L3 specimens mass loss rate is $0.2 \%, 0.11 \%,-0.06 \%$, respectively. Among them, the mass of L1, L2 group was slightly decreased after 180 times of dry wet cycle, while L3 group still increased the mass. From a whole point of view, the mass loss rate is a process that first decreases and then increases. The main reason is that the destruction of the crystalline salt of wet dry cycles is a very slow crystallization process, and the dry wet cycle is not sensitive to the mass loss rate of the samples. L1 test procession be divided into three stages, the first is mass increase stage; the second process is the mass loss rate of a gentle transition stage; the third procedure is test the mass of rapid decline stage, appeared mortar drop phenomenon. However, the L3 specimen group, the specimen density is higher, the sulfate solution is not easy to invade, so it is not easy to generate ettringite and gypsum. The mass loss rate has been negative in the 180 sulfate wet and dry cycles, and the surface and the interior of the specimen have not been destroyed obviously. From the cycle of the end of the mass loss rate, L1 test pieces of the highest mass loss rate, L3 group of the lowest loss rate. It can be concluded the smaller the w/c ratio, the stronger the ability to resist sulfate attack.

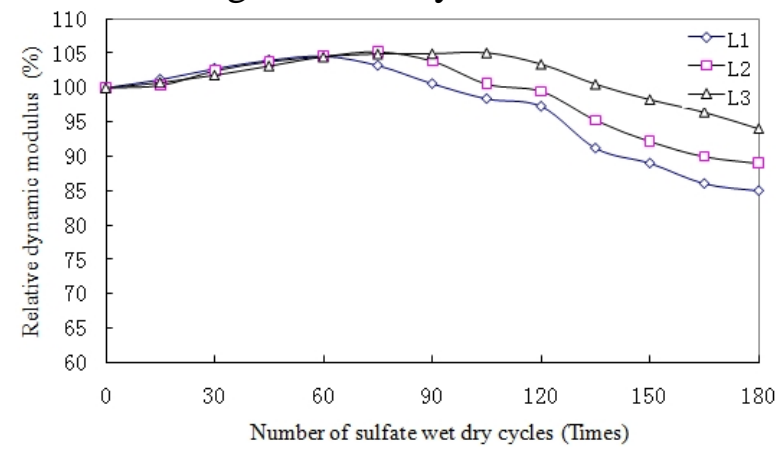

Figure 4. Relative dynamic modulus loss in sulfate attack.

It can be concluded from Figure 4: before the 75 wet and dry cycles, L1, L2, L3 specimens relative dynamic modulus change have little difference. After the 75 freeze-thaw cycles, the relative dynamic modulus of L3 group began to decrease. And L1, L2 group also experienced a rise in the process of. After the arrival of the 180 dry wet cycles, the L1, L2 and L3 specimens relative dynamic elastic modulus was $84.96 \%, 89.02 \%, 94.02 \%$, respectively. The w/c ratio of 0.38 have highest relative dynamic elastic modulus after 180 sulfate cycles of sulfate attack. The w/c ratio of 0.45 test components through 180 sulfate attack cycles, the relative dynamic elastic modulus is the smallest. L3 specimens of the w/c ratio is low, the structure is compact, which can resist greater pressure, so have greater relative dynamic elastic modulus than L1, L2 specimens. W/C ratio of panel concrete has a certain effect on the resistance of sulfate attack, the w/c ratio is smaller, the panel concrete resistance to sulfate attack ability is stronger. 


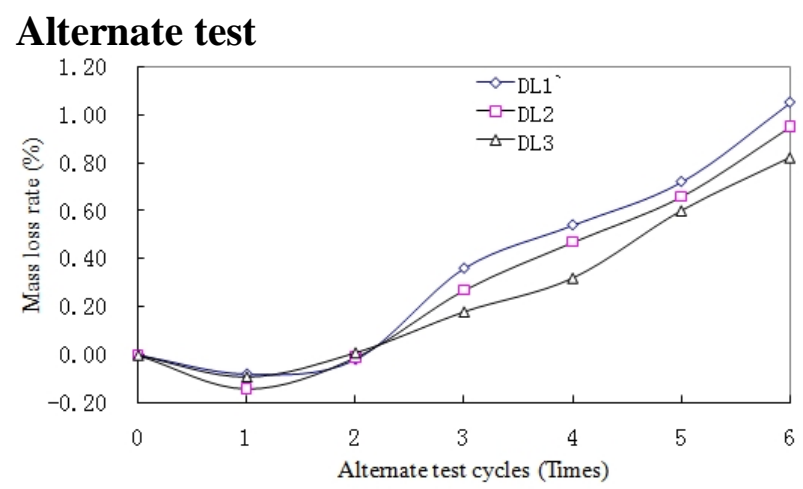

Figure 5. Mass loss in alternate test.

It can be concluded from Figure 5: in the first two cycles of alternate test, each group specimens $\mathrm{n}$ increased in the mass, and the mass loss rate of the three groups is equal at this time. With the increase of the number of cycles, the mass loss rate of each group showed a different growth trend, DL1 growth was the fastest, and DL3 was the slowest. Analysis of reasons: mainly due to the impact of w/c ratio on the mass loss rate of the test pieces, the small w/c ratio specimens have less space, dense structure, high strength, so it can prevent the sulfate liquid through the panel concrete. After 6 cycles, the mass loss rates of DL1, DL2 and DL3 in the three groups were $1.05 \%, 0.95 \%, 0.82 \%$, respectively. As can be seen in the freeze-thaw cycles and sulfate wet dry cycle alternating test, w/c ratio is an important influencing factor. When the w/c ratio smaller, frost resistance of concrete face and resistance to sulfate erosion durability is better; w/c ratio is larger, the panel of frost resistance and resistance to sulfate erosion durability worse.

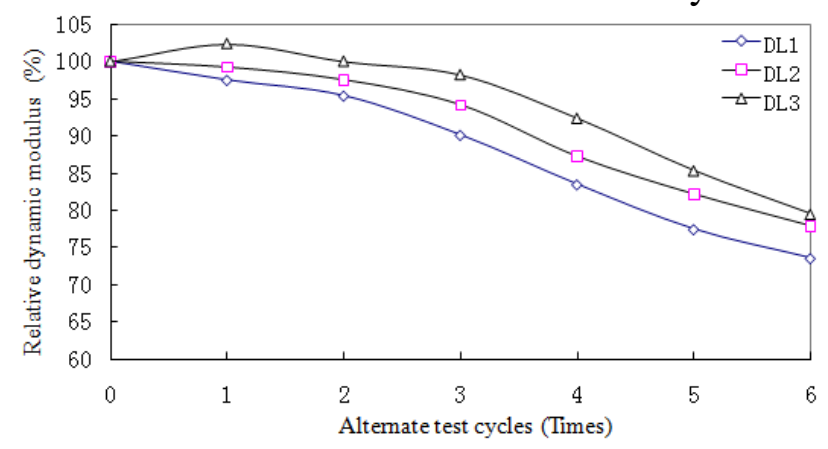

Figure 6. Relative dynamic modulus loss alternate test.

It can be concluded from Figure 6: the relative dynamic modulus of the 3 groups can be divided into two stages: the first stage is a relatively gentle decline in the relative modulus (1 2 cycles). The second stage is accelerating decreased stage ( $4 \sim 6$ cycles). The relative dynamic modulus of the specimen is decreased greater. After 6 cycles, the dynamic modulus of DL1, DL2 and DL3 were $73.56 \%, 77.89 \%$ and $79.59 \%$, respectively. It can be seen that the relative dynamic modulus of the DL1 specimen is the lowest, which indicates that the test piece is the most serious. DL1 with the water cement ratio of 0.45 concrete specimens, it is concluded that: the greater the w/c ratio, the worse the performance of the concrete frost resistance and sulfate resistance.

\section{Comparison between alternating test and single test}

Alternate circulation 6 times, has experienced the freeze-thaw cycle 150 times, sulfate wet and dry cycle 90 times. The mass loss rate and relative dynamic modulus of elasticity were shown in Table 2 and 3:

From the results of the superposition of the mass loss rate in Table 2, after 150 freeze-thaw cycles and 90 sulfate attack cycles, the w/c ratio of $0.45,0.42,0.38$ panel concrete have the mass loss rate of $0.08 \%,-0.075 \%,-0.08 \%$, respectively. After the coupled destruction of freeze-thaw and sulfate attack alternate test, the concrete mixtures with w/c ratio of $0.45,0.42,0.38$ have the mass loss rate of $1.05 \%, 0.95 \%, 0.82 \%$, respectively. The mass loss rate of the former is obviously smaller than that of the latter. 
From the results of the superposition of the mass loss rate in Table 3, after 150 freeze-thaw cycles and 90 sulfate attack cycles, the relative dynamic elastic modulus of the concrete mixtures with w/c ratio of $0.45,0.42,0.38$ is $95.49 \%, 97.42 \%$ and $98.73 \%$, respectively. After the coupled destruction of freeze-thaw and sulfate attack alternate test, the concrete mixtures with w/c ratio of $0.45,0.42$, 0.38 have the mass loss rate of $1.05 \%, 0.95 \%, 0.82 \%$, respectively. The relative dynamic modulus of the former is larger than that of the latter, and the modulus of elasticity is decreased by $21.56 \%$, $19.53 \%, 19.19 \%$, respectively.

The degree of coupled deterioration of the specimens after freeze-thaw cycles and sulfate attack is more serious than that of single sulfate attack and freeze-thaw cycles. Mainly it is because of freezethaw and sulfate attack early can produce a network of fine cracks. When the sulfate attack cracks accelerated the freeze-thaw damage, and the freeze-thaw cracks also accelerated the sulfate attack. Single freeze-thaw cycles and single sulfate attack damage, which has no interaction effect of these two kinds of cracks, so the degree of coupled deterioration of the alternating test is higher.

Table 2. The superposition results of mass loss.

\begin{tabular}{llll}
\hline Specimen group & D1 & D2 & D3 \\
\hline $\begin{array}{l}\text { Mass loss rate after 150 cycles of freeze- } \\
\text { thaw }\end{array}$ & 0.36 & 0.10 & 0.04 \\
Specimen group & L1 & L2 & L3 \\
Mass loss after 90 cycles of sulfate attack & -0.20 & -0.25 & -0.20 \\
Superposition results & 0.08 & -0.075 & -0.08 \\
\hline
\end{tabular}

Table 3. The superposition results of relative loss modulus.

\begin{tabular}{|c|c|c|c|}
\hline Specimen group & D1 & D2 & D3 \\
\hline $\begin{array}{l}\text { Relative dynamic modulus after } 150 \\
\text { cycles of freeze-thaw }\end{array}$ & 90.42 & 91.00 & 92.45 \\
\hline Specimen group & L1 & $\mathrm{L} 2$ & L3 \\
\hline $\begin{array}{l}\text { Relative dynamic modulus after } 90 \text { cycles } \\
\text { of sulfate attack }\end{array}$ & 100.56 & 103.83 & 105.01 \\
\hline Superposition results & 95.49 & 97.42 & 98.73 \\
\hline
\end{tabular}

\section{CONCLUSIONS}

The following conclusions have been drawn from this experimental work:

(1) The w/c ratio has great influence on the freeze-thaw and sulfate attack resistance of panel concrete. The smaller of w/c ratio, the stronger of the freeze-thaw and sulfate attack resistance of panel concrete. According to the 300 freeze-thaw cycles, the freeze-thaw cycles can be divided into three stages: the first stage is an acceleration decreased period ( 0 125 cycles). The second stage with the surface mortar drop, freeze-thaw of the destruction of the panel concrete is relatively slow (125 200 cycles). In the third stage with the aggregates droping, the deterioration rate of the test is accelerated (200 300 cycles). Sulfate attack test can also be divided into three stages. During the first is test the mass or relative dynamic elastic modulus increased with the sulfate attack cycles ( $0 \sim 75$ cycles); the second stage is the mass or relative dynamic elastic modulus with a smooth transition stage (75 120 cycles); the third stage is the mass of the specimen or the relative dynamic elastic modulus decreased rapidly process (120 180 cycles).

(2) With the increase of alternate test cycles, the coupled deterioration of freeze-thaw cycles and sulfate attack accelerates the deterioration of durability properties of panel concrete. The mass loss rate of concrete specimens under the alternate test was significantly increased, and the relative dynamic 
modulus was significantly reduced. The coupled factors of freeze-thaw cycles and sulfate attack is not a simple superposition of the effects, it is the super superposition effect.

\section{REFERENCES}

1) Ge, Y. \& Yang, W.C. 2005. Research on the frost resistance of concrete in sulfate solution. Concrete 25 (8): 71-79.

2) Gao, R.D. \& Li, Q.B. 2013. Concrete deterioration mechanisms under combined sulfate attack and flexural loading. Journal Material Civil Engineering 25 (1):39-44.

3)Liu, L.X. 2001. Brief introduction on the study of erosion and prevention of concrete in salt lake and saline soil area of Chaerhan. Journal of Building Materials 4 (4), 395-400.

4)Li, Y. \&Wang R.J. 2015. Study on durability of panel concrete under combined actions of freezethaw cycle and sulfate attack. Journal of Water Resources and Water Engineering 26(5):177-181.

5)Liang, W.Q. \& He, Y. 2009.Study on durability of high content fly ash concrete face slab. China concrete and cement products 43(2):2-4.

6) Ma, Y.M. \& Huang Y.Y. 2001 Research on crack resistance and durability of concrete face slab. Water power, 2001, 4(8): 26-30.

7) Wang, Y.L. \& Yao, Y. 2001. Researches on key engineering concrete durability and applications. China Building Material: Beijing.

8)Wang D.K. \& Li Y.P. 1998. Test and study on the slab concrete for the dam of Xiaoshan Hydropower Station. Water power 20(5):18-21.

9) Yang, D.F. \& Ma, F.L. 2004. Research on crack resistance and durability of concrete faced rockfill dam with concrete face rockfill dam. Proceedings of the International Symposium on hydraulic power generation: Beijing. 